\title{
Digitally Controlled Transconductor Based on a Quantum Transconductance
}

\author{
Hervé Barthélemy \\ IM2NP - UMR 7334 \\ Université de Toulon (UTLN) \\ 83957 La Garde Cedex, France \\ herve.barthelemy@univ-tln.fr
}

\author{
Remy Vauché \\ IM2NP - UMR 7334 \\ Aix-Marseille Université (AMU) \\ 38, Rue Joliot Curie \\ F - 13451 Marseille Cedex 20 \\ remy.vauche@im2np.fr
}

\author{
Sylvain Bourdel \\ IMEP-LAHC \\ Grenoble INP - Minatec \\ 3 Parvis Louis Néel - BP 50257 \\ 38016 Grenoble cedex \\ sylvain.bourdel@minatec.inpg.fr
}

\begin{abstract}
A new CMOS digitally controlled negative-transconductance amplifier (DTA) and an application example of a 4-Bits-Digitally Controlled Oscillator (DCO) are presented in this paper. The DTA is based on the traditional Digital CMOS inverter topology. From simulation and under 1.2 volts supply voltage, the proposed DCO oscillates from $375 \mathrm{MHz}$ to $475 \mathrm{MHz}$ which is compatible with the Medical Implant Communication Service (MICS) frequency band. The maximum total power consumption is about $2.5 \mathrm{~mW}$ and only $2.5 \mathrm{nW}$ in power-off mode. All simulations have been performed using a CMOS $130 \mathrm{~nm}$ process design kit from STMicroelectronics.
\end{abstract}

\section{INTRODUCTION}

Today Transconductance Amplifiers are used to design several continuous time ' $\mathrm{gm}-\mathrm{C}$ ' circuits for analog processing, which are, in several cases, filters and oscillators [1-10]. Transconductance amplifier is also used in numerous analog front-ends based sensors and instrumentation networks. The interest of the gm-C topologies is that they could operate at high frequency [1]; they also give the advantage of using a capacitor as loading impedance that is compatible with the digital supply voltage $\mathrm{V}_{\mathrm{DD}}$. Moreover the transconductance of the amplifier stage can be used to simulate a resistance which is adjustable. High performances radiofrequency and instrumentation front-ends also need high precision filters and oscillators and consequently the cut-off frequency (filters) or the frequency of oscillation (oscillators) must be calibrated. From literature frequency calibration could be done by capacitor switching or by modifying the transconductance values $[2,3,4,12]$. Amplitude calibration is also often realized by controlled the gain from a transconductance. For all the reasons, discussed below, the controlled transconductance amplifier plays an essential role to process continuous time signals. The amplifier transconductance is traditionally modified from a voltage controlled current source (VCCS) $[4,12]$. After calibration, the controlled voltage is save analogically in a capacitor [11]. In this case, the system needs to regularly refresh the calibration because of the capacitance discharge [11]. Digitally-controlled-current-source offers the advantage to save and controlled the transconductance from a digital word which can be save in a memory device. In this case the transconductance tuning precision is directly correlate to the current source quantum $[4,12]$. In this paper we propose to consider directly a transconductance quantum. This idea has been previously proposed by [4] in the design of a CMOS programmable OTA. For a transconductance quantum equal to $\mathrm{g}_{0}$ the target transconductance $\left(\mathrm{g}_{\mathrm{m}}\right)$ is controlled from a $n$ bits $\mathrm{A}<\mathrm{n}-1: 0>$ digital control number (voltage), we have:

$$
g_{m}=\left[\sum_{j=1}^{n}\left(A_{j} \cdot 2^{j}\right)\right] g_{0}=A_{\text {Base } 10 \cdot g_{0}} \quad A j €[0,1]
$$

where $\mathrm{g}_{0}$ is the quantum transconductance. The output of the transconductance amplifier is equivalent to a current source, then it is also easily, by added in parallel a transconductance amplifier (transconductance $\mathrm{g}_{\mathrm{H}}$ ), to obtain:

$$
g_{m}=g_{H}+\sum_{j=1}^{n}\left(A_{j} \cdot 2^{j}\right) g_{0}
$$

Due to the non-linearity, equations (1) and (2) are generally quasi-valid at small signal amplitude operations only. To maintain a linear relationship between the input and output, i.e. at moderate amplitudes or high amplitude variations, it is necessary that the transconductance remains constant. Literature proposes a large number of solutions to improve the linearity; a number of solutions is based on the source degeneration technique $[5,9,13]$.

Single ended input-output transconductance amplifier using the traditional CMOS two transistors inverter demonstrates interesting properties. These properties are low area, good linearity and the capacity to operate at very high frequency under very low supply voltage $[1-3,6-7,10,14]$. The main drawback of the traditional CMOS inverter is the relative difficulty to control the bias current in order to modify the transconductance; in this way an elegant solution by acting on the bulk bias voltage is proposed in [3]; however this solution necessitates a relatively complex bulk-control circuitry that increases the silicon area and power consumption. Another classical solution is based on a double CMOS pair source degeneration [2] to control the transconductance; this last solution necessitates to process signal with a relatively low transconductance gains due to the source degeneration. The Idea, presented in this paper concerns a new transconductance amplifier topology based on a "quantum transconductance" $\mathrm{g}_{0}$ and a multiple of this quantum. In this paper, the proposed transconductance is discussed in session 2 and session 3 . In session 4, application based on the design of a digitally controlled oscillator (DCO) is proposed, discussed and simulated using the typical parameters of the CMOS $130 \mathrm{~nm}$ process from STMicroelectronics [15]. As an example we have choose a frequency range compatible with the Medical Implant Communication Service (MICS) frequency band [16]. Finally a conclusion is given in section $\mathrm{V}$.

\section{ONE BIT Digitally CONTROLED NEGATIVE TRANSCONDUCTANCE}

The proposed one-bit transconductance topology is shown in Fig.1a and its corresponding conventional symbol in Fig.1b. The transistors $M_{1}$ and $M_{2}$ realize the analog processing [12,6] while $M_{3}$ to $M_{10}$ realize the digital operation. Not 
represented in Fig.1, all pmos bulks are connected to $\mathrm{V}_{\mathrm{DD}}$ and all nmos bulks to the ground (gnd).
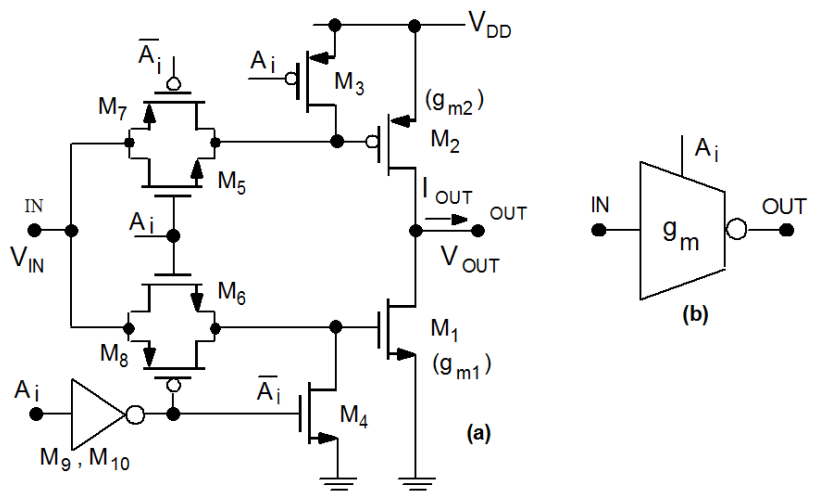

(b)

Fig.1: Proposed 1bit Negative Transconductor: -a- Transistor configuration -b- proposed symbol

Transistor $M_{1}$ and $M_{2}$ are sized to be equilibrate [6]; this leads to a common mode $\mathrm{DC}$ bias voltage $\mathrm{V}_{\mathrm{DD}} / 2=\mathrm{V}_{\mathrm{IN} 0}=\mathrm{V}_{\text {OUT0 }}$. $\mathrm{V}_{\text {IN0, }}, \mathrm{V}_{\text {OUT0 }}$ correspond to the DC part of $\mathrm{V}_{\text {IN }}(\mathrm{t}), \mathrm{V}_{\text {OUT }}(\mathrm{t})$ respectively. In Fig.1a,b the input digital voltage $A_{i}$ is a 1 bit digit that control the transconductance amplifier. Transistors $M_{3}$ to $M_{10}$ are used to switch-off the amplifier, allowing to manage the power consumption and to provide $\mathrm{g}_{\mathrm{m}}=0$ when $\mathrm{A}_{\mathrm{i}}=0$. From Fig.1a, the transconductance of the proposed amplifier, is given by:

$$
\begin{array}{ll}
\mathrm{g}_{\mathrm{m}}=\mathrm{g}_{\mathrm{m} 1}+\mathrm{g}_{\mathrm{m} 2} & \text { when } A_{\mathrm{i}}=1\left(\mathrm{~V}_{\mathrm{DD}}\right) \\
\mathrm{g}_{\mathrm{m}}=0 & \text { when } \mathrm{A}_{\mathrm{i}}=0(\mathrm{gnd})
\end{array}
$$

Where $g_{\mathrm{m} 1}$ and $g_{\mathrm{m} 2}$ are the gate-source transconductances of $\mathbf{M}_{1}$ and $\mathbf{M}_{2}$ respectively. Note that this amplifier provides a negative transconductance gain for $A_{i}=1$.

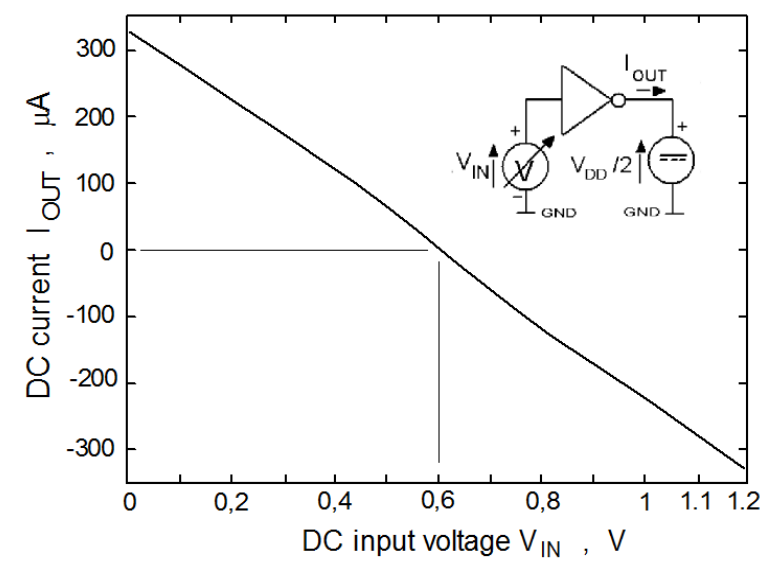

Fig.2: Typical DC characteristic of the amplifier output current versus the input voltage when $A_{i}=1 ; 130 \mathrm{~nm}$ CMOS process from STMicroelectronics $[15], \mathrm{g}_{\mathrm{m}}=0.548 \mathrm{~m} \Omega^{-1}$

With $\mathrm{A}_{\mathrm{i}}=1$, around $\mathrm{V}_{\mathrm{DD}} / 2, \mathrm{M}_{1}$ and $\mathrm{M}_{2}$ operate in saturation mode for which the drain currents are approximate to [17]:

$$
\begin{aligned}
\mathrm{I}_{\mathrm{DS} 1}= & \left(\beta_{1} / 2\right)\left(\mathrm{V}_{\mathrm{GS} 1}-\mathrm{V}_{\mathrm{T} 1}\right)^{\mathrm{n}}\left(1+\lambda_{1} \mathrm{~V}_{\mathrm{DS} 1}\right) \\
\mathrm{I}_{\mathrm{SD} 2}= & \left(\beta_{2} / 2\right)\left(\mathrm{V}_{\mathrm{SG} 2}-\left|\mathrm{V}_{\mathrm{TP} 2}\right|\right)^{\mathrm{n}}\left(1+\lambda_{2} \mathrm{~V}_{\mathrm{DS} 2}\right) \\
\quad & \beta_{1}=\mu_{1} \mathrm{C}_{\mathrm{OX}} \mathrm{W}_{1} / \mathrm{L}_{1} ; \quad \beta_{2}=\mu_{2} \mathrm{C}_{\mathrm{OX}} \mathrm{W}_{2} / \mathrm{L}_{2}
\end{aligned}
$$

Where $n \in(1-2)$; $C_{O X}$ is the thin oxide capacitance by meter square; $V_{T 1}$ and $V_{T 2}$ are the $M_{1}$ and $M_{2}$ threshold voltages respectively. $\mu 1$ and $\mu 2$ the $M_{1}$ and $M_{2}$ motilities; $W_{1} / L_{1}$ or $\mathrm{W}_{2} / \mathrm{L}_{2}$ is the ration between the transistors channel width and length. Considering an equilibrate inverters: $\beta_{1} \cong \beta_{2}$, and it will be considered in this paper that $\beta=\beta_{1}=\beta_{2}$. Fig. 2 shows the typical variation of the output current versus the input voltage $\mathrm{V}_{\text {IN }}$. For $\mathrm{Ai}=1$, at small signal amplitude, the transconductance of the proposed DTA using an equilibrate CMOS inverter is:

$$
\left.\mathrm{g}_{\mathrm{m}}\right|_{\mathrm{V}_{\mathrm{IN} 0}=\mathrm{V}_{\text {OUT } 0}=\mathrm{V}_{\mathrm{DD}} / 2}=-\frac{\delta \mathrm{I}_{\mathrm{OUT}}}{\delta \mathrm{V}_{\mathrm{IN}}}
$$

In Fig. 1, the output current of a CMOS inverter is: $\mathrm{I}_{\mathrm{OUT}}=\mathrm{I}_{\mathrm{SD} 2}-\mathrm{I}_{\mathrm{DS} 1}$; where $\mathrm{I}_{\mathrm{DS} 1}$ and $\mathrm{I}_{\mathrm{SD} 2}$ are the current through the drain-source of $\mathrm{M}_{1}$ and $\mathrm{M}_{2}$ respectively. For $\mathrm{V}_{\mathrm{IN}}=\left(\mathrm{V}_{\mathrm{DD}} / 2\right)+\Delta \mathrm{V}_{\mathrm{IN}}$ and neglecting the channel length modulation, the output current $\mathrm{I}_{\mathrm{OUT}}$ is given, from equations (4), by $[6,8]$ :

$$
\mathrm{I}_{\mathrm{OUT}}=\frac{\beta}{2 .}\left[\left(\frac{\mathrm{V}_{\mathrm{DD}}}{2}-\Delta \mathrm{V}_{\mathrm{IN}}-\mid \mathrm{V}_{\mathrm{T} 1}\right)^{\mathrm{n}}-\left(\frac{\mathrm{V}_{\mathrm{DD}}}{2}+\Delta \mathrm{V}_{\mathrm{IN}}-\mathrm{V}_{\mathrm{T} 2}\right)^{\mathrm{n}}\right]
$$

In equation ( 7$): \mathrm{I}_{\text {OUT }}=\mathrm{I}_{\mathrm{OUT} 0}+\Delta \mathrm{I}_{\mathrm{OUT}}$, with $\mathrm{I}_{\mathrm{OUT} 0}=0$. Considering $\mathrm{V}_{\mathrm{T} 1}$ approximately equal to $\left|\mathrm{V}_{\mathrm{T} 2}\right|\left(\mathrm{V}_{\mathrm{T} 1}=\left|\mathrm{V}_{\mathrm{T} 2}\right|=\mathrm{V}_{\mathrm{T}}\right)$, we have [6] for $\mathrm{n} \cong 2$ :

$$
\Delta \mathrm{I}_{\mathrm{OUT}}=-\beta\left(\mathrm{V}_{\mathrm{DD}}-2 \mathrm{~V}_{\mathrm{T}}\right) \Delta \mathrm{V}_{\mathrm{IN}}=-\mathrm{g}_{\mathrm{m}} \Delta \mathrm{V}_{\mathrm{IN}}
$$

Equation (8) and the simulation proposed in Fig.2 show a good linear relationship between $\Delta \mathrm{I}_{\text {OUT }}$ and $\Delta \mathrm{V}_{\text {IN }}$. The CMOS inverter around $\mathrm{V}_{\mathrm{DD}} / 2$ also provides a very good frequency performance; because the frequency transition of the CMOS equilibrate inverter around $\mathrm{V}_{\mathrm{DD}} / 2$ is approximately the half of the transition frequency of $\mathrm{M}_{1}$ (nmos) $[6,8]$.

\section{N-BITS DigGITALLY CONTROLED TRANSCONDUCTOR AMPLIFIER BASED ON QUANTUM TRANSCONDUCTANCE}

The proposed digitally $N$ Bits controlled transconductance amplifier (DTA) topology is shown in Fig.3a; with an example of a control word $\mathrm{A}<3: 0>$, i.e. $N=4$; In Fig. $3, \mathrm{~A}_{0}$ is the less significant bit (LSB) and $\mathrm{A}_{3}$ the most significant bit (MSB) of $A<3: 0>$. The equivalent symbol of the proposed DTA in Fig.3a is draw in Fig.3b.

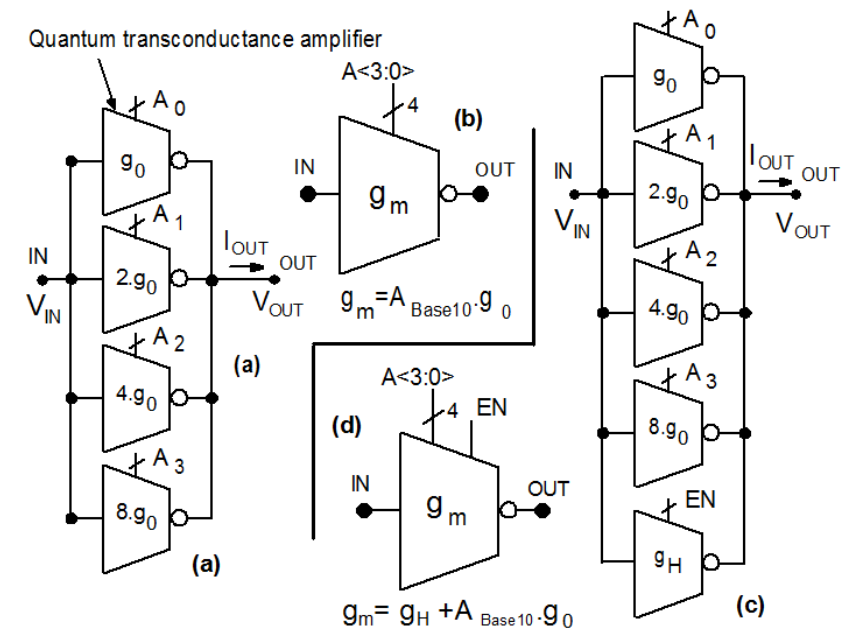

Fig. 3: Propose digitally controlled transconductance amplifiers: -a- configuration that verify equation (1) and -b- the proposed equivalent symbol -c- configuration that verify equation (2) and -d- equivalent symbol 
The 4-bits DTA is constructs by connecting in parallel 4 identical 1-bit DTAs (Fig.1). The DTA of gain $\mathrm{g}_{0}$ is the quantum transconductor. The transconductance $2 \mathrm{~g} 0$ is obtained by doubling the transistor channel widths of $\mathrm{M}_{1}$ and $\mathrm{M}_{2}$. The same sizing operation is done between $4 \mathrm{~g}_{0}$ and $2 \mathrm{~g}_{0}$ amplifiers and between $8 \mathrm{~g} 0$ and $4 \mathrm{~g}_{0}$ amplifiers; here the length of all transistors are supposed to be equal. The amplifier in Fig. 3 respects the equation (1). To realize a 4bits-DTA that verify equation (2) an additional transconductance amplifier of transconductance $\mathrm{g}_{\mathrm{H}}$ controlled by the digit $\mathrm{EN}$ is added in parallel. This derivate amplifier is shown in Fig.3c and its proposed symbol in Fig.3d. Note that the amplifier in Fig.3c,d is powered off for $\mathrm{EN}=0$ and $\mathrm{A}<3: 0>=0$.

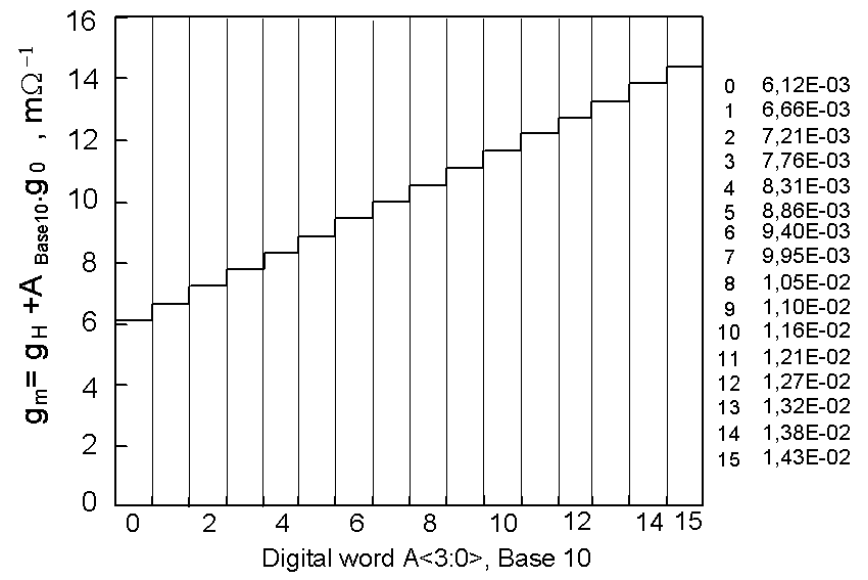

Fig.4: Simulation of the 4Bits DTA in Fig.3c 130nm CMOS process from STMicroelectronics [15], size reported in Table 2 of section IV.

\section{MICS-BAND-RADIOFREQUENCY OSCILLATOR BASED DIGITALLY CONTROLLED TRANSCONDUCTORS}

To illustrate the capabilities of using digitally controlled transconductance amplifier (DTA), simulation results and discussion of a compact active oscillator [8], using the DTA, in section 2 and 3 , is proposed in this section. The compact oscillator topology [8] is shown in Fig. 5. The Circuit has been design to be able to operate in the MICS band [16]. Table I resume the transistor channel widths and the circuits transconductances obtained from simulations. Simulation have been performed using typical BSIM4 transistor models and the associated design kit of the CMOS $0.130 \mu \mathrm{m}$ process from STM [15]; the length $\mathrm{L}$ of all transistors has been fixed to $\mathrm{L}=0.2 \mu \mathrm{m}$.

Table I: Transistors Width in $[\mu \mathrm{m}]$ and equivalent transconductance values in $\left[\Omega^{-1}\right], \mathrm{V}_{\mathrm{DD}}=1.2 \mathrm{~V}, \mathrm{~L}=0.2 \mu \mathrm{m}$.

\begin{tabular}{c|c|c|c|c|c|c}
\hline $\begin{array}{c}\text { Ibit } \\
\text { Amplifiers }\end{array}$ & $\begin{array}{c}\boldsymbol{g}_{\boldsymbol{m}} \\
{\left[\Omega^{-1}\right]}\end{array}$ & $\begin{array}{c}\boldsymbol{M}_{\boldsymbol{I}} \\
{[\mu \mathrm{m}]}\end{array}$ & $\begin{array}{c}\boldsymbol{M}_{\mathbf{2}} \\
{[\mu \mathrm{m}]}\end{array}$ & $\begin{array}{c}\boldsymbol{M}_{\mathbf{5} / 6 / 7 / 8} \\
{[\mu \mathrm{m}]}\end{array}$ & $\begin{array}{c}\boldsymbol{M}_{\mathbf{3} / \mathbf{9}} \\
{[\mu \mathrm{m}]}\end{array}$ & $\begin{array}{c}\boldsymbol{M}_{\mathbf{4} / \mathbf{1 0}} \\
{[\mu \mathrm{m}]}\end{array}$ \\
\hline $\mathrm{g}_{0}$ & $5.48 \mathrm{e}-4$ & 1 & 2.75 & 0.15 & 2.75 & 1 \\
\hline $\mathrm{g}_{\mathrm{H}}$ & $6.12 \mathrm{e}-3$ & 12 & 33 & 18 & 2.75 & 1 \\
\hline $\mathrm{g}_{\mathrm{N}}$ & $6.02 \mathrm{e}-4$ & 1.1 & 3.02 & 1.65 & 2.75 & 1 \\
\hline $\mathrm{g}_{\mathrm{P}}$ & $5.45 \mathrm{e}-4$ & 1 & 2.75 & 1.5 & 2.75 & 1 \\
\hline $\mathrm{g}_{\mathrm{Q}}$ & $5.45 \mathrm{e}-4$ & 1 & 2.75 & 1.5 & 2.75 & 1 \\
\hline
\end{tabular}

In Fig.5, the DTAs having the transconductance $\mathrm{g}_{0}, \mathrm{~g}_{\mathrm{Q}}, \mathrm{g}_{\mathrm{N}}$ and $\mathrm{g}_{\mathrm{P}}$ correspond to the 1bit-DTA topology in Fig. 1a while the DTA having the transconductance $\mathrm{g}_{\mathrm{A}}$ is the 4Bits-DTA architecture of Fig.3c.

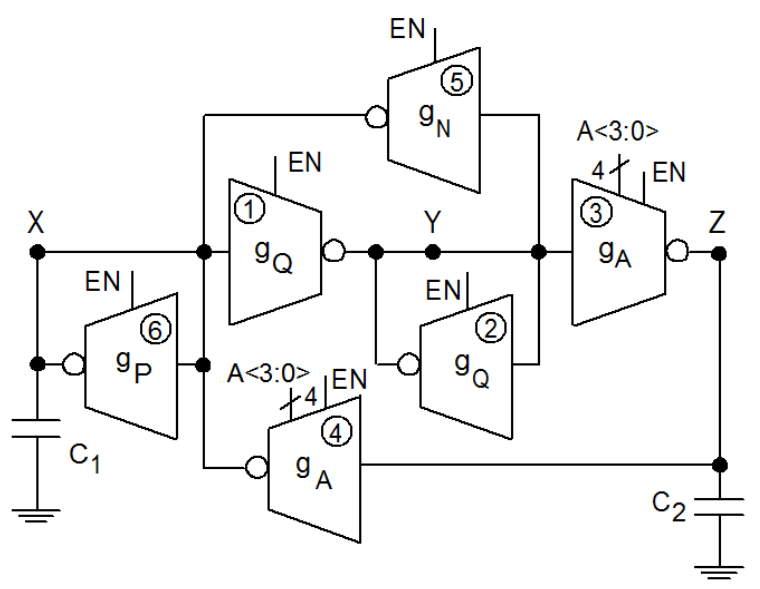

Fig.5: Compact Active RLC oscillator based transconductor [8].

The Digitally Controlled Oscillator (DCO) in Fig. 5 has only 3 nodes $\mathrm{X}, \mathrm{Y}$ and $\mathrm{Z}$. At node $\mathrm{X}$ : the DTA-(5) simulates a negative resistance equal to $\mathrm{R}_{\mathrm{NEG}}=-1 / \mathrm{g}_{\mathrm{N}}$; The DTA-(6) simulates a positive resistance $R_{P O S}=1 / g_{P}$.. Between node $X$ (input) and Z (output), DTA-(1), DTA-(2) and DTA-(3) simulate a positive transconductance amplifier. Because DTA-(4) is a negative transconductance amplifier, we found that [DTA(1) (2) (3)], DTA-(4) and $\mathrm{C}_{2}$ form a Gyrator [8]. This gyrator simulate at node $\mathrm{X}$ a single ended inductance $\left(\mathrm{L}_{2}\right)$ which is, from Fig.5, is given by:

$$
\mathrm{L}_{2}=\mathrm{C}_{2} / \mathrm{g}_{\mathrm{A}}^{2}
$$

The equivalent circuit at $\mathrm{X}$ node is shown in Fig.6 [8].

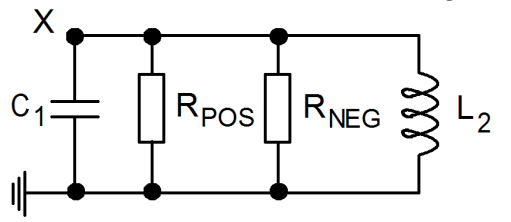

Fig.6: Equivalence of the compact DCO at node X.

Note that when $\mathrm{EN}=0$ and $\mathrm{A}<3: 0>=0000$, the $\mathrm{DCO}$ is in standby mode (power off); in oscillation mode $\mathrm{EN}=\mathrm{V}_{\mathrm{DD}}$. The ideal frequency of oscillation of the DCO $\left(f_{\mathrm{OSC}}\right)$ and condition of oscillation $(\mathrm{CO})$ are, $\mathrm{EN}=\mathrm{V}_{\mathrm{DD}}$ :

$$
\mathrm{CO}: \quad \mathrm{g}_{\mathrm{N}} \geq \mathrm{g}_{\mathrm{p}} \quad ; \quad f_{0}=\frac{1}{2 \pi \sqrt{\mathrm{L}_{2} \mathrm{C}_{1}}}=\frac{\mathrm{g}_{\mathrm{A}}}{2 \pi \sqrt{\mathrm{C}_{1} \mathrm{C}_{2}}}
$$

Considering equations (2) and (3), it follows that:

$$
f_{\mathrm{OSC}}=f_{\mathrm{MIN}}+\mathrm{A}<3: 0>. f_{0}
$$

With $f_{\mathrm{MIN}}=\mathrm{g}_{\mathrm{H}} / 2 \pi \sqrt{\mathrm{C}_{1} \mathrm{C}_{2}}$ and $f_{0}=\mathrm{g}_{0} / 2 \pi \sqrt{\mathrm{C}_{1} \mathrm{C}_{2}}$

$F_{\text {MIN }}$ is the minimum frequency of operation; $\mathrm{f}_{0}$ can be viewed as the quantum frequency and $\mathrm{A}<3: 0>f_{0}$ the tuned frequency in the MICS band [16]. The ideal maximum MICS-band frequency is then: $f_{\mathrm{MAX}}=f_{\mathrm{MIN}}+15 . f_{0}$. Fig. 7 shows the simulation variation of $f_{\mathrm{OSC}}$ versus the digital 4 bits word control $\mathrm{A}<3: 0>$. Including the parasitic effects, an approximation of $\sqrt{\mathrm{C}_{1} \mathrm{C}_{2}}$ is $\sqrt{\mathrm{C}_{1} \mathrm{C}_{2}}=2.6 \mathrm{pF}$. A deviation with equation (12) are mainly caused by the variations of the gate-source $\left(\mathrm{M}_{1}, \mathrm{M}_{2}\right)$ parasitic 
capacitances and conductances $\left(\mathrm{M}_{1}, \mathrm{M}_{2}\right)$ with value varies with $\mathrm{A}<3: 0>$. The equivalent parasitic capacitances at node $\mathrm{X}$ also introduce some deviation between simulation and the ideal equation (12).

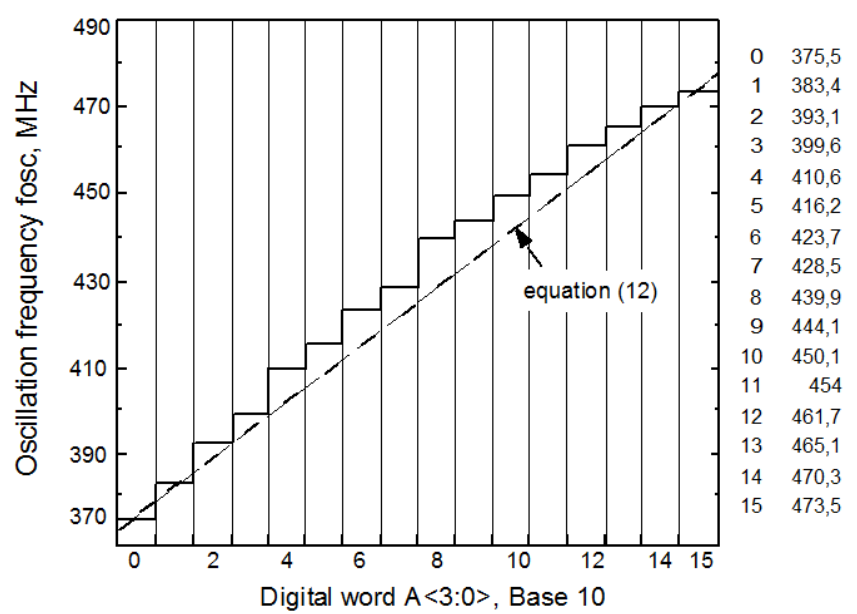

Fig.7: DCO oscillation frequency $f_{\text {osc }}$ versus $\mathrm{A}<3: 0>$.

Fig. 8 shows typical oscillation waveforms obtained at $\mathrm{X}, \mathrm{Y}$ and $\mathrm{Z}$ nodes.

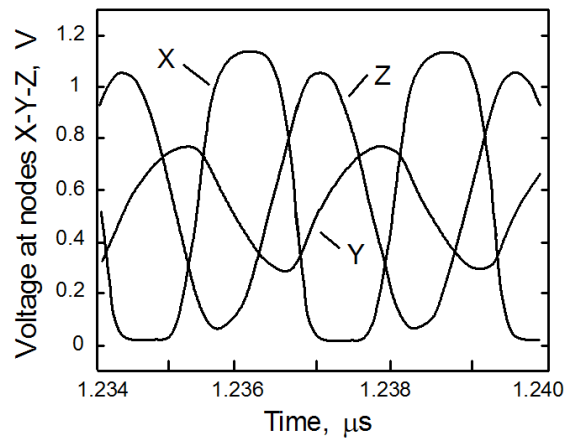

Fig.8: DCO Waveform voltages at $\mathrm{X}, \mathrm{Y}, \mathrm{Z}$ nodes.

Table II resumes the main simulation characteristics of the proposed DCO. The dynamic current consumption through $\mathrm{V}_{\mathrm{DD}}$, for all value of $\mathrm{A}<3: 0>$ is shown in Fig. 9.

Table II: DCO main parameters

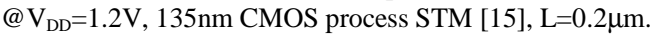

\begin{tabular}{c|c|c}
\hline parameters & values & scales \\
\hline Quantum Frequency $f_{0}$ & 6.5 & {$[\mathrm{MHz}]$} \\
\hline Tuning Range $\left[f_{\mathrm{MIN}}-f_{\mathrm{MAX}}\right]$ & $375-473$ & {$[\mathrm{MHz}]$} \\
\hline Ioff $(E N=0, A=0)$ & 13.1 & {$[\mathrm{nA}]$} \\
\hline Total power consumption $(\mathrm{A}=15)$ & 2.5 & {$[\mathrm{~mW}]$} \\
\hline
\end{tabular}

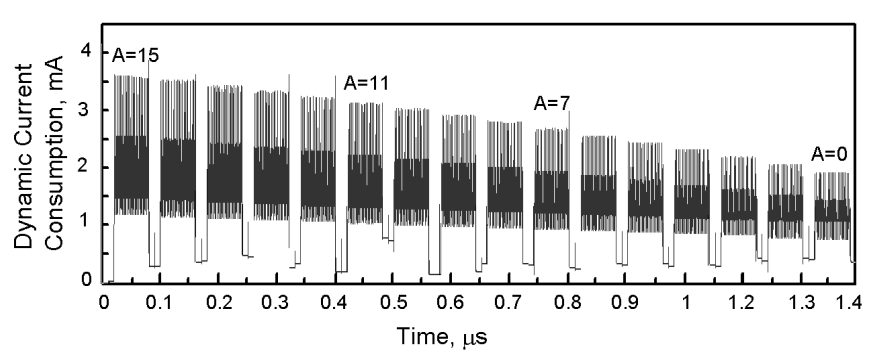

Fig.9: Current consumption versus time for $A_{B a s e 10}=15$ to $A_{B a s e 10}=0$

\section{CONCLUSION}

Principle and simulation of a new digitally controlled negative transconductance amplifier (DTA) has been proposed in this paper. The proposed DTA will be a useful design block for several analogue applications that need digital controlled VCCS. The proposed topology can operate at ultra-low voltage supply because the power-off mode is not made from a serial standby-pmos between the supply voltage and the internal circuit; but also because the DTA is based on the simple 2 transistors CMOS inverter. In addition to the advantage of operating at low supply voltage, the transconductor can work at large signal amplitudes and at high signal frequency.

\section{REFERENCES}

[1] B. Nauta : "A CMOS transconductance-C filter technique for very high frequencies", IEEE Journal of Solid-State Circuits, vol. 27, no. 2, 1992, pp. $142-153$.

[2] A. Pirmohammadi, M. H. Zarifi : "A low power tunable Gm-C filter based on double CMOS inverters in $0.35 \mu \mathrm{m}$ ", Analog Integrated Circuits and Signal Processing, Vol. 71, Issue 3, 2012, pp. 473-479.

[3] S. Vlassis : "0.5V CMOS inverter-based tunable transconductance", Analog Integrated Circuits and Signal Proceecing, issue 1, 2012, pp. 289-292.

[4] B. Pankiewicz, M. Wojcikowski, S. Szczepanski, Y. Sun : "A Field Programmable Analog Array for CMOS Continuous-Time OTA-C Filter", IEEE Journal of Solid-State Circuits, Vol. 37, n ${ }^{\circ}$ 2, 2002, pp. 125-136.

[5] S. Koziel, S. Szczepanski : "Design of Highly Linear Tunable CMOS OTA for Continuous-Time Filters", IEEE transaction on circuits and Systems, Analog and Digital signal processing, vol. 49, n², 2002, pp. 110-122.

[6] H. Barthelemy, S. Meillere, J. Gaubert, E. Kussener : "Transconductance CMOS inverter based AC coupling amplifier", New Circuits and Systems Conference (NEWCAS), 2014 IEEE 12th International (NEWCAS), 2014, pp. 9-12.

[7] A. Villegas, D. Vázquez, E. Peralías, A. Rueda : “A 3.6mW @ 1.2V High Linear 8th-order CMOS Complex Filter for IEEE 802.15.4 Standard', 2011, pp. 99-102

[8] H. Barthelemy, S. Bourdel, J. Gaubert, M. Battista : "CMOS inverters based high frequency voltage controlled sinusoidal oscillator", 14th IEEE International Conference on Electronics, Circuits and Systems, 2007. ICECS 2007, pp. $490-493$.

[9] J-H Weng, C-Y. Yang : "An Active Gm-C Filter Using a Linear Transconductance", IEEE Conference on Electron Devices and SolidState Circuits (EDSSC), 2007, pp. 909-912.

[10] H. barthelemy, S. Meillere, J. gauvert, N. Dehaese, S. Bourdel : “OTA based on CMOS inverters an applications in the design of tunable bandpass filter"; Analog Integrated Circuits and Signal Processing, vol. 57, 2008, pp. 160-178.

[11] D. J. Groeneveld, H. J. Schouwenaars, H. A. H. TerMeer, C. A. A. Bastiaansen : "A self-calibration technique for monolithic high resolution D/A converter", IEEE Journal of Solid-State Circuits, vol. 24, $\mathrm{n}^{\circ}$ 6, 1989, pp. 1517-1522.

[12] H. Samavati : "Variable transconductance mixer system", US PATENT $\mathrm{n}^{\circ}$ US 12/204, 310, publication number US7847613 B1, 2007.

[13] R.L. Nagaraj, D. Yagain: "Design and Implementation of a Linear Transconductance Amplifier with a Digitally Controlled Current Source", International conference on Emerging trends in engineering and tecjnology (ICETET), 2011, pp. $274-279$.

[14] B-K. Kim, D. Im, J. Choi, K. Lee: "A Highly Linear $1 \mathrm{GHz} 1.3 \mathrm{~dB} \mathrm{NF}$ CMOS Low-Noise Amplifier With Complementary Transconductance Linearization", IEEE Journal of Solid-State Circuits, Vol.. 49, $\mathrm{n}^{\circ} 6$, 2014, pp. 1286-1302.

[15] CMP : "IC's Manufacturing : "CMOS 130nm (HCMOS9GP)", MultiProject Circuits ${ }^{\circledR}$, http://cmp.imag.fr/products/ic/?p=STHCMOS9.

[16] B. Ghafari, L. Koushaeian, F. Goodarzy : "An ultra low power and small size PLL for wearable and implantable medical sensors", $2^{\text {nd }}$ IEEE International Worshop on Consumer eHealth Plateforms, Services and Applications, 2012, pp. 409-412.

[17] P. Antognetti, G. Massobrio : "Semiconductor device modeling with spice", Mc Graw Hill, Int. Edition, Electronics Engineering Series, 1988. 